\title{
An Evaluation of Proposed Formula 1 Aerodynamic Regulations Changes Using Computational Fluid Dynamics
}

\author{
Robert L. Perry ${ }^{*}$ and David D. Marshall ${ }^{\dagger}$ \\ Aerospace Engineering Department, California Polytechnic State University, San Luis Obispo, CA 93407-0352
}

\begin{abstract}
This report evaluates the proposed FIA Formula 1 World Championship aerodynamics rules changes intended to increase on track passing for the 2009 season. Two full Formula 1 cars were modeled under close drafting conditions, both under the current regulations and the proposed 2009 regulations to determine whether or not the FIA's goals of reducing down force by $50 \%$ and improving sensitivity to leading car wakes would be met. Under the current regulations, a car following another at 2.4 car lengths loses approximately $17 \%$ of its down force compared to isolation. The new regulations were counter productive and ineffective, failing both to reduce down force by $50 \%$ and lower that $17 \%$ performance detriment. Instead the cars became more sensitive - losing $26 \%$ of their down force in 2009 compared to $17 \%$ under current conditions. Though the new cars create an overall cleaner wake, the wake's effects are now concentrated near parts of the car which were previously insensitive.
\end{abstract}

\section{Nomenclature}

$C_{D} \quad=\quad$ drag coefficient

$C_{L} \quad=$ lift coefficient

$C_{p} \quad=$ pressure coefficient

\section{Introduction}

A $\mathrm{s}$ a spectator sport, Formula 1 has been the most popular in the world for years. Bringing the world's best drivers as well as its most talented engineers and scientists into a single realm, Formula 1 provides the human and technological spectacle that captivates audiences and transcends cultural and international boundaries. But as budgets have increased into the hundreds of millions of US dollars per season, technological development, particularly aerodynamic performance, has stifled driver competition. Aerodynamic down force produced by wings and ground effects has become so great that the cars' upwash and vortices dramatically reduce the performance of following cars - enough to prevent passing and competitive racing. This presents an obvious problem for drivers looking for a level playing field, and for spectators who wish to see a race full of passing and unpredictable outcomes. A race where the same car maintains position throughout the entire race is not entertaining. Thus, the reduction of upwash and trailing vortices is of crucial importance to the viability of the sport.

Formula 1's governing body - the Federation Internationale de L'Automobile (FIA) responded in late 2006 by clamping down on the aerodynamic regulations for 2009. These new regulations ${ }^{1}$ will ban the complicated bodywork, winglets, and aerodynamic suspension members between the front and rear axles. The rear wing is reduced in span but raised in height to weaken its coupling with the underbody diffuser, and the front wing is moved closer to the ground to reduce sensitivity to other cars' wakes and increase the use of ground effect. Together, these measures are expected to cut down force and drag by $50 \%$. While the FIA asserts the changes will be significant and positive, the effectiveness of the FIA's proposed solution has yet to be investigated, and the impact these regulations could have on the sport is publicly unknown. The purpose of this research is to compare the aerodynamic coupling and performance of Formula 1 cars under the current and 2009 regulations, evaluating the effectiveness of the rules changes and their potential to improve the racing spectacle.

\footnotetext{
* Graduate, 1 Grand Avenue, San Luis Obispo, CA 93407-0352, Student Member

† Assistant Professor, 1 Grand Avenue, San Luis Obispo, CA 93407-0352, Senior Member
} 


\section{Methods}

Analytic solutions are impossible and wind tunnel testing would be too costly for a preliminary, investigative study. Thus, CFD was used exclusively. A Formula 1 car meeting the proposed 2009 regulations was simulated both in isolation and following an identical car at 2.4 car lengths. A 2007 car was also simulated under the same two conditions, to quantify the effectiveness of the rules as an improvement. With these four cases, the performance of the 2009 cars and their sensitivity to each other when in proximity could be compared to current Formula 1 cars.

Most external components of a Formula 1 car are designed with aerodynamic performance as the main, if not only, objective. These components are highly coupled and interdependent, which means most of them cannot be reasonably examined in isolation. The shear number of parts which have significant aerodynamics effects, along the coupling between them requires the inclusion of the full car for testing or simulation of any components. Thus for all the four cases, full Formula 1 car models were used.

\section{Mesh Generation}

Mesh generation was completed using ICEM CFD 11.0.12, whose features were well suited to complex geometries. Meshes created were a hybrid mix of hexahedral, tetrahedral, and prism cells that allowed for the most appropriate cell type to be used in each area of the domain. Tetrahedral cells were necessary in the flow volume immediately surrounding the cars in order to capture the geometry. Tetrahedral cells can represent any surface geometry while maintaining exceptionally low cell skewness, and, unlike ICEM's structured meshes, can be generated using parallel processing. However, for the flow volume away from the car, lower cell count is desired because of the smaller gradients. Hexahedral cells are better suited for the far field domain because they can be generated faster, reduce cell count, and also reduce numerical diffusion and increase accuracy. A major advantage of hexahedral cells is that they require less interpolation than unstructured cells, which reduces error and improves stability. While impractical near and around complex geometries, hexahedral cells offer superior performance for the rest of the domain.

To capture boundary layer effects along walls, prism cells were necessary to achieve the level of refinement and

$\mathrm{y}+$ values required to resolve such small flow features. Tetrahedral cells are ill suited for boundary layers because of aspect ratio and skewness considerations. The resulting topology is an unstructured tetrahedral and prism block around the geometry with a large hexahedral domain. Figure 1 below depicts this mesh topology.

Figure 1. Mesh topology for a 2007 car in isolation cells downstream grow at a lower rate of 5\% to capture the wake, while cells in front of, above, and to the side of the car grow at a more aggressive $22 \%$

By specifying appropriate mesh sizes on surfaces, all geometric features are resolved. Most CFD mesh generation software have the ability to manually specify mesh density on each surface, and others extend that further by allowing surfaces to be grouped into parts which share mesh settings. ICEM CFD allows for both, and both features were used extensively. Most meshing packages also have curvature and proximity refinement features, which allow the user to specify a single mesh size for a surface or part and let the software refine in regions of curvature or proximity to other parts and surface intersections. This is a particularly useful feature for scripting batch runs, where minimal user effort is the driver. 
But for complicated problems, automatic refinement produces excessive cells counts by over-refining unimportant features. Curvature refinement can also results in cells small enough to enter gaps in the geometry or result in extreme skewness. Thus for large or complicated problems where mesh quality and cell count are bigger driver than user effort, the extra labor associated with manually specifying mesh settings on each surface is worthwhile. For all full car models, mesh sizes were specified manually on all surfaces. The result is shown in Figure 2 below, where surfaces with identical mesh settings share a common color. Appendix A presents additional images which highlight the surface mesh of the 2007 car as well as the mesh topology of Figure 1 applied to two car models.

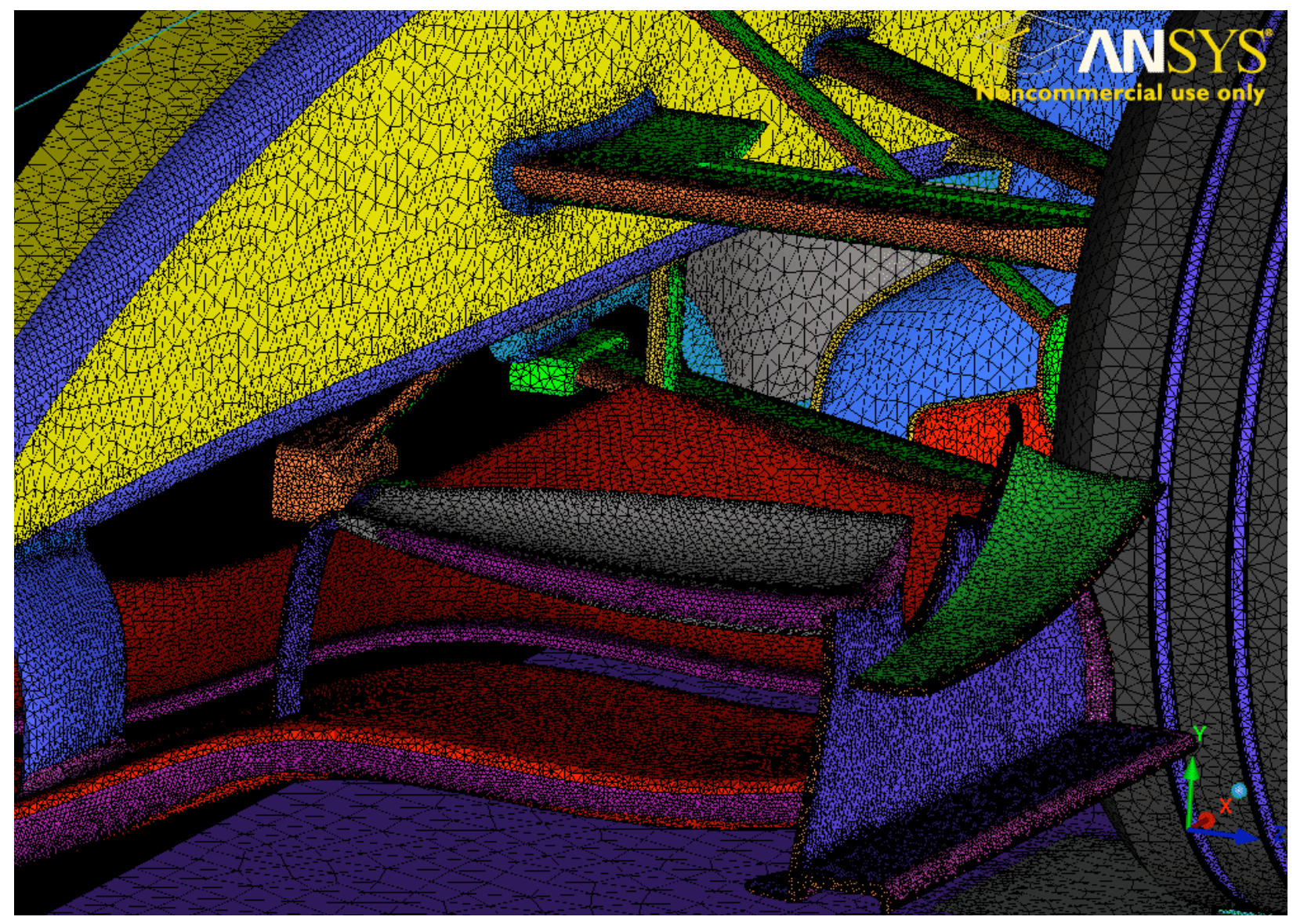

Figure 2. Front end mesh detail for a 2007 car

For wall boundaries, wall functions were employed to reduce cell count and skew. Wilcox asserts that the use of wall functions reduces accuracy ${ }^{3}$, but cell count is greatly reduced in doing so. Furthermore, for a comparative study, such levels of accuracy were not worth the effort and solving time (see Section III for details). The target $\mathrm{y}^{+}$ of 60 was selected to ensure cells would not be located in the buffer region while keeping the initial prism layers small enough to fit in acute angle corners and allow more than one cell to fit inside the boundary layer. Contours of $\mathrm{y}+$ for a full car solution are given in Appendix A.

The surface mesh captures the geometry, but an appropriate volume mesh captures the flow features. The volume mesh around the car is unstructured tetrahedral, with regions of increasing levels of refinement where important flow features are expected to form. Manually specifying refinement levels maintains flow capture without excessive cell count in areas away from the geometry. Figure 3 shows the effect of this manually specified refinement at the rear wing of a 2007 car. Further images in Appendix A illustrate the volume mesh and the placement of the mesh refinement volumes within ICEM CFD. Total mesh sizes were 19 and 14 million cells for single 2007 and 2009 cars, respectively, and approximately 30 and 40 million cells for dual car 2007 and 2009 car models. 


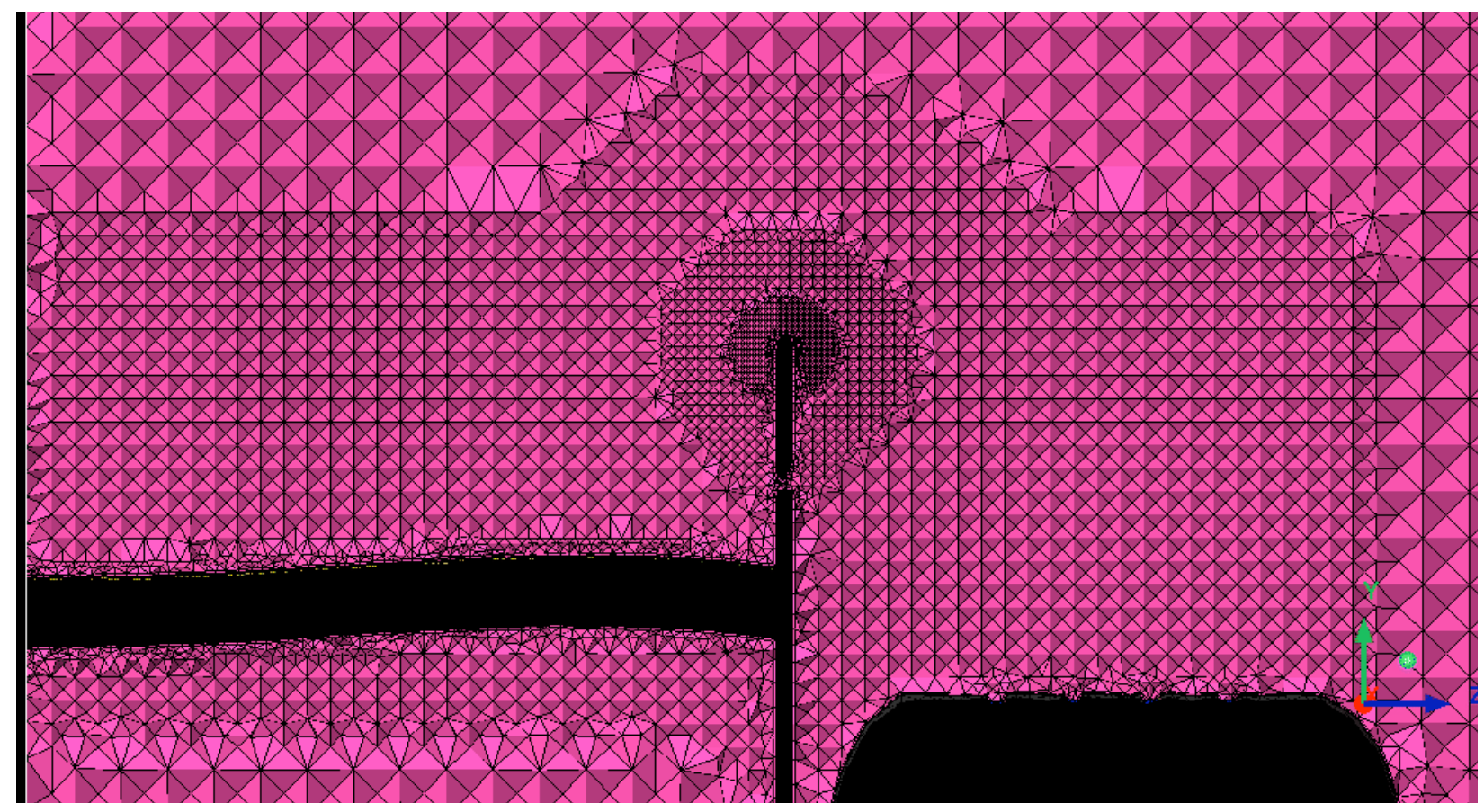

Figure 3. Rear wing volume mesh controlled growth rates and volumes where cell size is constrained gradually refine the mesh up to point of high gradient, such as the endplate tips where powerful vortices form

\section{Solver Models}

Fluent 6.3.26's incompressible solver was used exclusively, due to the low speed nature of the flow. Density and stagnation density differ by less than $1 \%$ even at peak Mach number, so the use of a compressible solver was assumed superfluous. A fixed velocity inlet upwind and atmospheric pressure outlet downwind along with a moving ground plane below the car were used to define a vehicle forward speed of $60 \mathrm{~m} / \mathrm{s}$. Velocity profiles over a 2006 race lap from Larsson ${ }^{5}$ show that $60 \mathrm{~m} / \mathrm{s}$ represents a good average speed for a typical race circuit. Symmetry planes were used elsewhere, and the domain extended over 12 car lengths behind the car and 6 car lengths in front of, above, and to the side of it. Such a large domain was selected to ensure the fixed conditions on the boundaries would not prove unrealistic and adversely affect the solution. All cases were run without yaw or crosswinds and thus a symmetry plane was used to eliminate the need to mesh both sides of the vehicle, which is a symmetric car.

The k- $\varepsilon$ turbulence model was chosen because it offered greater accuracy for the mesh and solving methods chosen for this research (see Section III for details). Other details of the solver, such as turbulence parameters at the boundary conditions, can be obtained from Perry ${ }^{6}$.

\section{Assumptions and Simplifications}

Formula 1 cars are complex systems that involve more than simple external flows. There are many internal cooling flows, engine combustion flows, and brake cooling flows which are coupled with the external aerodynamics. A major feature on the car is the radiator cooling ducts which draw their flow rates from the external flow around the car. Finely resolving engine combustion or the hundreds of cooling channels within the radiator was assumed to have a small effect on overall wake characteristics, so these features were replaced with simpler models.

The radiator was treated as a face through which a specified heat load was dissipated. This load was calculated using an assumed engine efficiency of $40 \%$ and a power output of $750 \mathrm{HP}^{7}$. The engine was replaced with a mass flow outlet where flow would leave the domain at a flow rate derived from the engine speed and displacement. The mass ratio of fuel within engine exhaust is small $\left(1 / 14^{\text {th }}\right)$, so the engine exhaust gas was introduced back into the domain as pure air at an elevated temperature. Because this examines the rules as they relate to increasing passing, the engine was assumed at peak power and RPM since both drivers would likely be exhausting all acceleration available. Full acceleration would require the brakes to be off, so transient heat transfer in the brakes was neglected for simplicity. 


\section{Validation}

Formula 1 is an extremely competitive and thus secretive industry, and raw wind tunnel or even CFD could not be found or published. In the absence of such data, validation cases were performed against other experimental data. The first case was a comparison with wind tunnel data from the NACA 4412 airfoil ${ }^{8}$, where different turbulence models and near wall treatments were used to evaluate the ability of each to predict separation. The results are the lift and drag polars presented in Figure 4 with and without wall the use of wall functions for two turbulence models (k- $\omega$ SST and $k-\varepsilon$ realizable.)
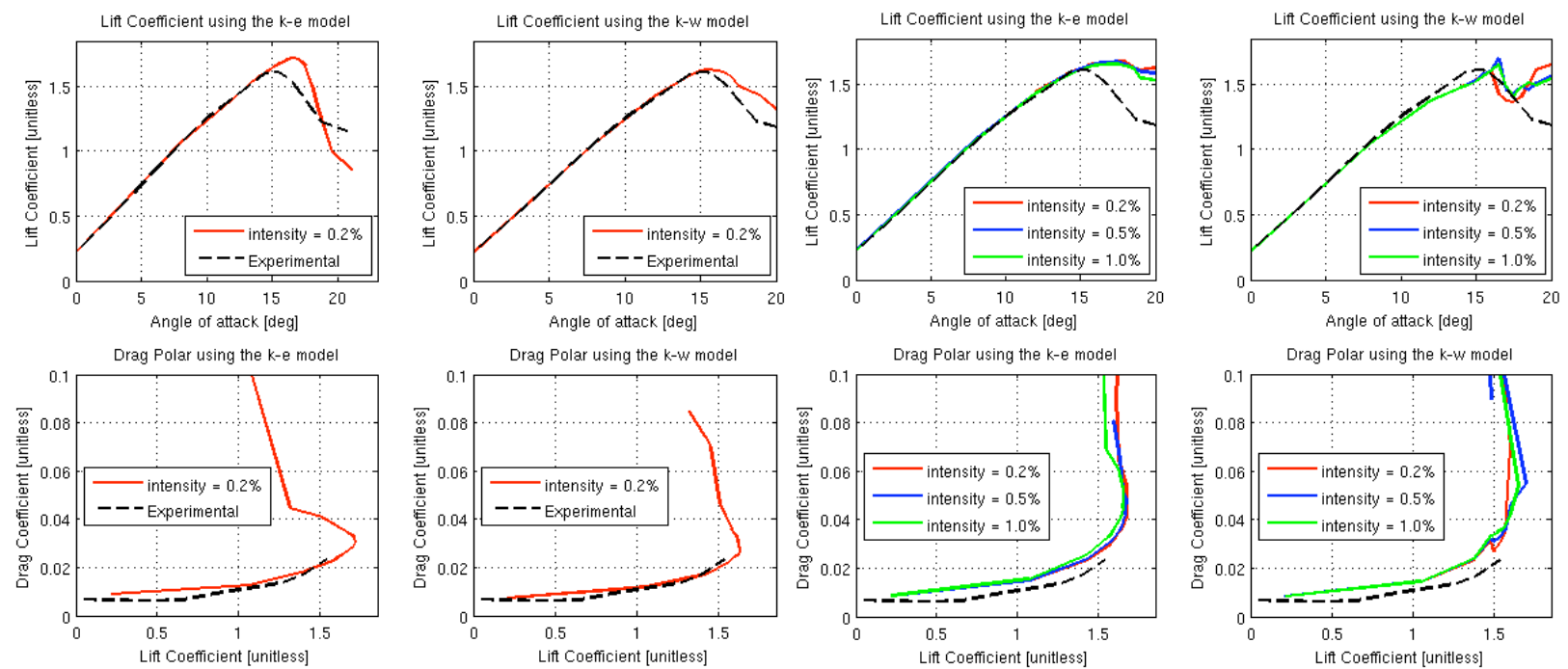

Figure 4. Lift and drag polars without (left half) and with (right half) wall functions

As illustrated in Figure 4, experimental correlation is generally good for both lift and drag. Complete discretization of the boundary layer without wall functions increases the accuracy of the drag values for both turbulence models, and the post stall lift values for the k- $\omega$ model. However the trends are well captured even with wall functions, and the accuracy of the k- $\varepsilon$ model is not really improved with the extra cells used to fully discretize the boundary layer. While Wilcox appears correct in that wall functions reduce accuracy for the k- $\omega$ model, but the difference between the k- $\varepsilon$ model with wall functions and the $k-\omega$ model without them is small. This is especially true considering that full boundary layer discretization for this 2-D case more than tripled cell count. Furthermore, this research is of a comparative nature where the ability to capture trends and differences is more important than capturing raw numerical values. The ability of wall functions to capture trends well while dramatically lowering cell count make them suitable, at least with the methods chosen for this research. And the k- $\varepsilon$ model's increased accuracy with wall functions makes it the superior turbulence model for this research.

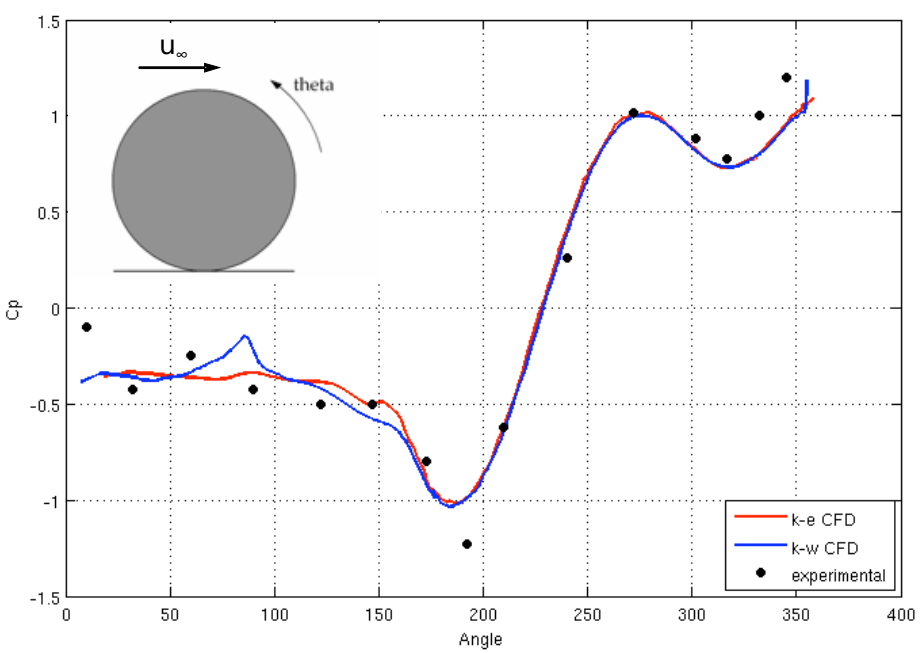

While winged surfaces are responsible for much of the wake upwash, the rotating tires are another critical wake element because of the blunt separation and stagnation pressure losses they create. Tires on open wheel cars are generally $40-50 \%$ of the total drag of the car $^{9}$, so an additional CFD case was compared to experimental wheel $\mathrm{Cp}$ data from Skea and Bullen $^{10}$. Figure 5 shows the experimental data points overlaid with CFD data for both $\mathrm{k}-\varepsilon$ and $\mathrm{k}-$ $\omega$ models. Note that the contact patch is a theta of zero. While nearly identical for both turbulence models, $\mathrm{k}-\omega$ produces more erratic behavior in the separation region (theta $<150$.) This is consistent with k- $\omega$ 's prediction of the NACA 4412 using wall functions for post-stall angles of attack.

Figure 5. Cp along a rotating wheel centerline 
The large and complicated nature of full car solutions eliminates the possibility for grid independence, as the NSF cluster used for solving was limited to models of approximately $80 \mathrm{M}$ cells. Thus grids that would be orders of magnitude or even 4-5 times larger than the baseline could not be solved. Such grid independence studies would require meshes of 100 to 400 million cells and nearly 500 GB of RAM to solve them. Facilities with these resources are rare and their availability is very low. Computing time on such machines is also costly. In lieu of this limit, a study was performed on one of the most complicated aerodynamic components of an F1 car: its front wing. Grid convergence on the front wing will indicate the mesh's ability to capture separation, high pressure gradients, ground effect, boundary layer dissipation, and complicated vortex flow interactions. While the precise point of grid convergence for the full car will still be unknown, applying mesh settings from a converged front wing to the full car is a strong indicator that the full car mesh will capture all of the important flow features.

An unstructured tetrahedral block surrounded the wing with 3-5 layers of prisms on each wall boundary, and hexahedral blocks representing the domain. This hybrid mesh was nearly identical to the full car's, as were the boundary conditions used. Three meshes were studied, and surface views of each are shown in . The first was a baseline using mesh settings that would ideally be used on the whole car. This mesh had approximately 3 million cells. The second was a larger mesh of nearly 12 million cells and the third a smaller, 500,000 cell mesh. While the extrema would have ideally been larger/smaller than 12/0.5 million cells, meshes smaller than 0.5 million cells became unrepresentative of the geometry, and meshes larger than 12 million cells had cells approaching the tolerance of holes and cracks in the CAD model.
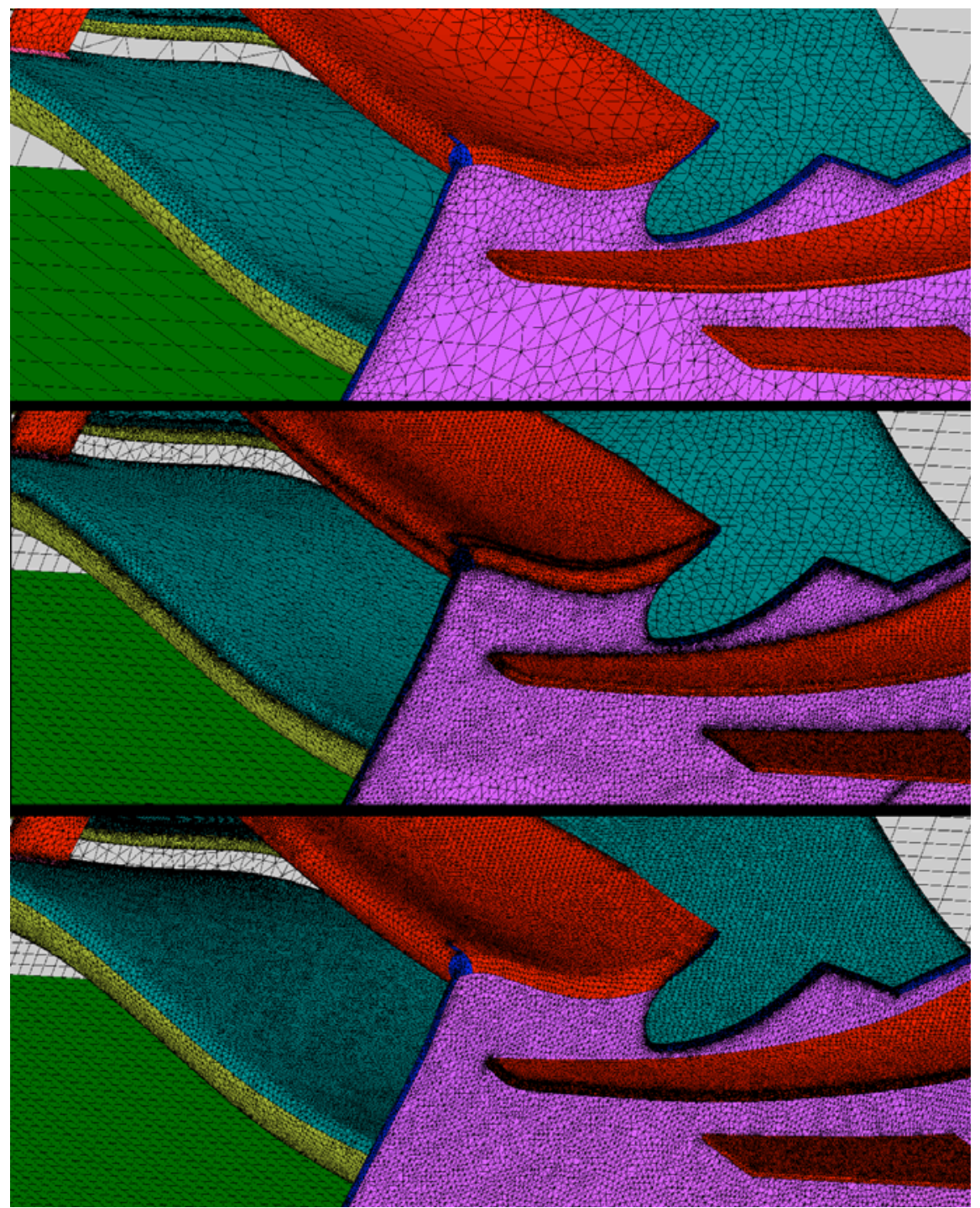

Figure 6. Leading edge surface mesh views 
The solutions were considered converged when the force monitors reached or oscillated about some constant value. After 1200 iterations, these criteria were met for all meshes studied. Throughout the grid convergence study the initial cell height for prisms layers remained constant in an effort to study the effects of volume mesh density and not $y^{+}$. The results of the study indicated that the baseline F1 car mesh would capture important flow features and correctly model the lift, drag, and wake characteristics of the car. As shown in Figure 7, the baseline mesh point of $3 \mathrm{M}$ cells was less than $1 \%$ off of the much finer $12 \mathrm{M}$ cell mesh for $\mathrm{C}_{\mathrm{L}}$, and the small mesh less than $1.8 \%$ off.

Perhaps even more interesting is the accuracy with respect to the values calculated with a Richardson extrapolation. The results for the coarse, baseline, and fine grids are each within $5.80,1.45$, and 0.48 percent of the continuum (zero cell size/infinite cell) values for $C_{D}$. Similar accuracy is observed for $\mathrm{C}_{\mathrm{L}}$, with errors of $1.79,0.28$, and 0.113 percent. These results suggest that the baseline mesh that reflects mesh settings used in the full car model (and even the coarse mesh) are sufficiently fine to capture the wing surface pressures and resulting force coefficients.

But in addition to capturing forces, the full car meshes must capture the wakes and vortex behavior between cars and individual components. Figure 8 shows velocity contours for each of the grids 1 chord length downstream. The colorbars and image settings are consistent between meshes, which are placed from top to bottom in order of increasing cell count. Further images of the wake 1.5 and 10 chord lengths downstream are given in Appendix B.
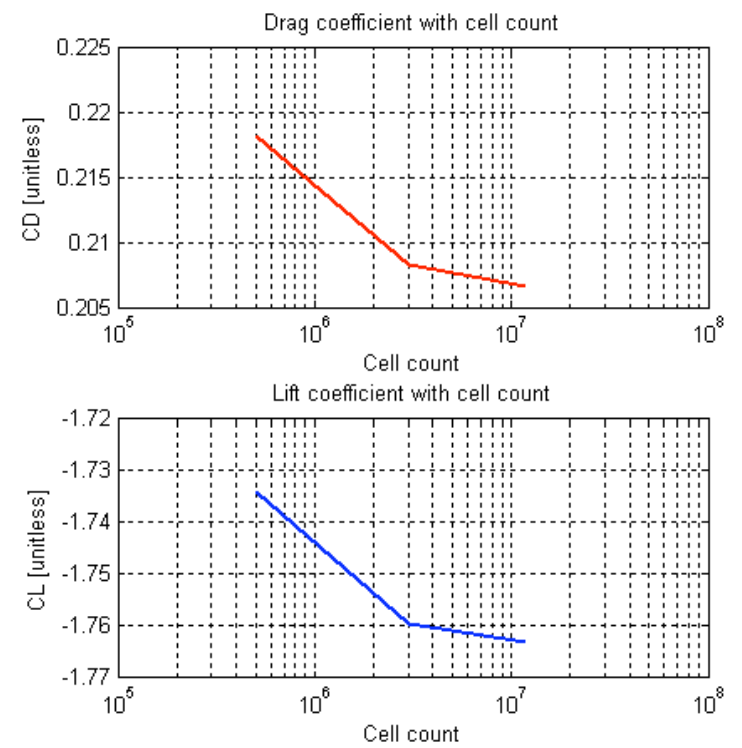

Figure 7. Grid independence results

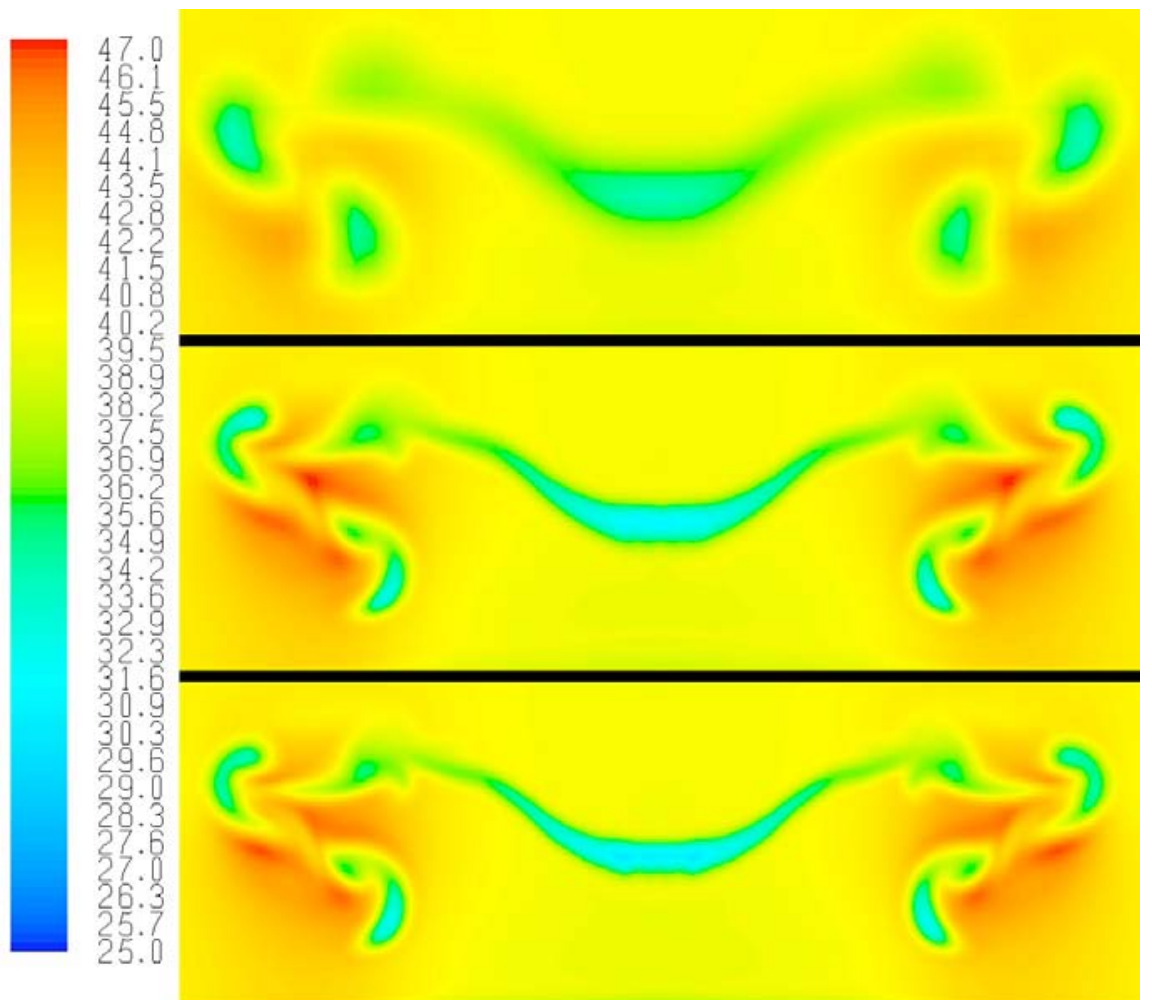

Despite capturing the forces, the $500 \mathrm{k}$ cell model fails to capture the wake just 1 chord length downstream. The vortices from the winglets, particularly those outside the endplate, are totally diffused. Dissipation of the boundary layer is similarly smeared across a larger region because of the larger cell size.

However, the 3 million cell baseline mesh, which represents mesh settings applied to the full car models, shows excellent wake capture and clear resolution of the major flow features.

Convection of the boundary layer downstream, several vortices, and high velocity cross flow are all visible with a level of detail that nearly matches the 12 million cell case. The vortices are captured in magnitude, shape, and location when compared to the mesh with 4 times more cells.

Figure 8. Velocity contours 1 chord length downstream 


\section{2007 Formula 1 Car}

Single 2007 car results illustrated a large loss in stagnation pressure and strong wake structures behind the car. When simulated with a second car 2.4 car lengths $(13.8 \mathrm{~m})$ behind the first, these wake structures had a significant effect visible in both the lift and drag figures and even on surface pressure contours. The effectiveness of aerodynamic surfaces on the following car were clearly compromised by the leading car's wake, so much so that down force on the following car was reduced by $17.3 \%$ compared to the same car in isolation. This figure is similar to studies on 2004 Formula 1 cars performed by the BMW Sauber F1 Team, who reported a 18\% loss in down force for similar down force ${ }^{5}$. While not conclusive proof, these figures suggest that the $17.3 \%$ drop found during this research is at least within reason. When the difference between 1rst and 10th place is tenths of a second per lap or less, a $17.3 \%$ reduction in aerodynamic performance is extremely significant. This huge performance detriment explains much of the difficulty drivers have in passing and the lack of on track action in recent years.

Figure 9 qualifies this number with contours of static pressure underneath the leading car (top) and following car (bottom). Examination of the cars' underbody shows no significant difference between the two, and the down force between the two undertrays is nearly identical. This is because dominant characteristic of the leading car's wake is upwash, which is an insignificant effect within 1-2 centimeters of the ground. However, the effect on the front and rear wing is considerably more significant. The following car's rear wing loses $24.1 \%$ of its down force, and the front wing $11.7 \%$. The front wing is considerably less sensitive, again because the upwash effects near the ground are less dominant. These down force losses are reflected in the cooler blues and greens seen on the lower surfaces of the front and rear wings, representing lower pressures.
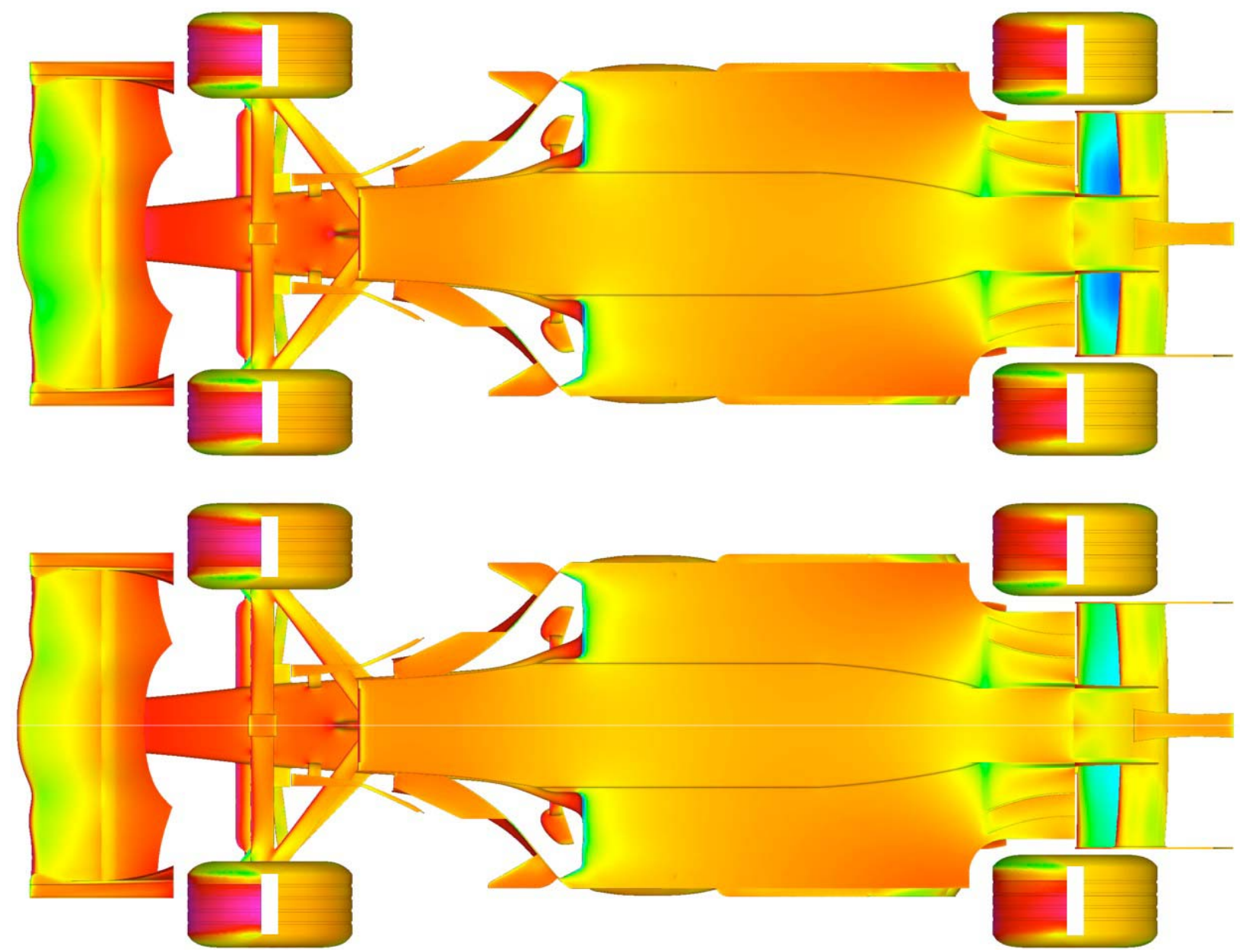

Figure 9. Static pressure underneath leading (top) and following (bottom) 2007 cars when drafting note: rear suspension is omitted for clarity

The larger losses for the rear wing cause an overall forward movement of the following car's center of pressure. This forward movement tends to reduce the stability of the vehicle and push the handling qualities towards oversteer 
- the unstable condition where the rear wheels lose tractive force first. Thus, there are two significant disadvantages to following cars under the 2007 regulations - significant down force loss and change in aerodynamic balance. In addition to penalties on the following car, there are also benefits to the leading car, most notably an increase in down force of nearly $1 \%$. Table 1 below shows the changes in drag and down force for cars in a lead-follow drafting situation, with a car in isolation as the baseline. Table 1 also highlights a small benefit for the trailing car: its drag decreases more than that of the leading car's.

Table 1. Effects of drafting on 2007 Formula 1 car

\begin{tabular}{|l|c|c|}
\hline & Down force vs. single car & Drag vs. single car \\
\hline Lead car & $+0.9 \%$ & $-8.4 \%$ \\
\hline Following car & $-17.3 \%$ & $-10.2 \%$ \\
\hline
\end{tabular}

\section{2009 Formula 1 Car}

While the 2009 regulations change almost every system on the car, the biggest and most visible changes will be made to the cars' external aerodynamics. Table 2 highlights some of the larger changes for 2009 by comparing them to the 2007 regulations. While there are many other changes, particularly to the regions where the main body of the car and vortex generators in front of it may exist, the reader is referred to the 2007 and 2009 technical regulations for such details. One of the largest changes outlined in Table 2 is the ban on winglets and tire scoops present on most current Formula 1 cars. The elimination of the vortices caused by these low aspect ratio elements is expected to reduce upwash in the wake significantly. Not only do these elements produce down force themselves, but their removal should also reduce rear wing down force because they are often strongly coupled with it.

Table 2. Comparison of the 2007 and 2009 aerodynamic regulations

\begin{tabular}{|c|c|}
\hline 2007 Regulation 2009 Regulation & 2007 Regulation 2009 Regulation \\
\hline \multicolumn{2}{|c|}{ Front wing } \\
\hline Front wing width no more than $1400 \mathrm{~mm}$ & Front wing no wider than $1800 \mathrm{~mm}$ \\
\hline Front wing no less than $150 \mathrm{~mm}$ above the ground & Front wing no less than $100 \mathrm{~mm}$ above the ground \\
\hline Body work between the axles no wider than $1400 \mathrm{~mm}$ & Body work between the axles no wider than $1600 \mathrm{~mm}$ \\
\hline Front wing no higher than $350 \mathrm{~mm}$ above the ground & Front wing no higher than $335 \mathrm{~mm}$ above the ground \\
\hline No restriction on cross sections between axles & No airfoil cross sections between front and rear wing \\
\hline Bodywork height may vary between axles & Body work height must decrease front to rear after the cockpit \\
\hline \multicolumn{2}{|r|}{ Rear wing } \\
\hline Rear wing span limited to $1000 \mathrm{~mm}$ & Rear wing span no greater than $800 \mathrm{~mm}$ \\
\hline Rear wing no higher than $800 \mathrm{~mm}$ from the ground & Rear wing no higher than $920 \mathrm{~mm}$ from the ground \\
\hline Rear wing no lower than $600 \mathrm{~mm}$ from the ground & Rear wing no lower than $740 \mathrm{~mm}$ from the ground \\
\hline 2 element rear wing & 2 element rear wing, no geometric or aerodynamic twist \\
\hline Rear wing leading edge behind rear axle & Rear wing leading edge $250 \mathrm{~mm}$ behind rear axle \\
\hline Maximum chord of $330 \mathrm{~mm}$; no restriction on variation & Maximum chord of $330 \mathrm{~mm}$; no spanwise variation \\
\hline \multicolumn{2}{|c|}{ Underbody } \\
\hline Rear diffuser no higher than $125 \mathrm{~mm}$ above the ground & Rear diffuser no higher than $100 \mathrm{~mm}$ above the ground \\
\hline No restriction within $150 \mathrm{~mm}$ of vehicle centerline & No bodywork within $360 \mathrm{~mm}$ of the ground in this area \\
\hline
\end{tabular}

Under the new regulations, down force and drag are indeed lowered. Upwash off the front wing is much weaker because of the upper element's removal and the ban on airfoil cross sections in the front suspension. Upwash and vortex flow behind the car is much weaker than with the 2007 car. Undertray down force is reduced by $48 \%$ and rear wing down force by approximately $26 \%$; greater than the reduction in planform area of $20 \%$. This greater than expected loss is a result of the severed coupling between the rear wing and other elements on the car. But overall, down force reductions fail to meet up to FIA expectations. Despite extensive modifications to the rules, down force for the 2009 car is $35 \%$ lower than in 2007 - well off the $50 \%$ target. Drag reductions are similarly off the mark only $17 \%$ compared to a target of $50 \%$. This is largely due to the increased drag of the wider tires which are, under the new rules, unshielded by bodywork.

Much like under the 2007 rules, down force losses for a following car are also similarly significant and visible through contours of static pressure underneath the car. Figure 10 shows contours of pressure underneath leading and 
following cars under the 2009 regulations. Figure 10 was generated on the same scale as the contours for the 2007 cars in Figure 9. Despite the measures taken by the FIA for 2009, the leading 2009 car still has a visible advantage over the following car. Though the tray contours are nearly identical, pressure contours for both wings are darker for the leading car. These darker blues and greens show significantly higher down force levels for the leading car.
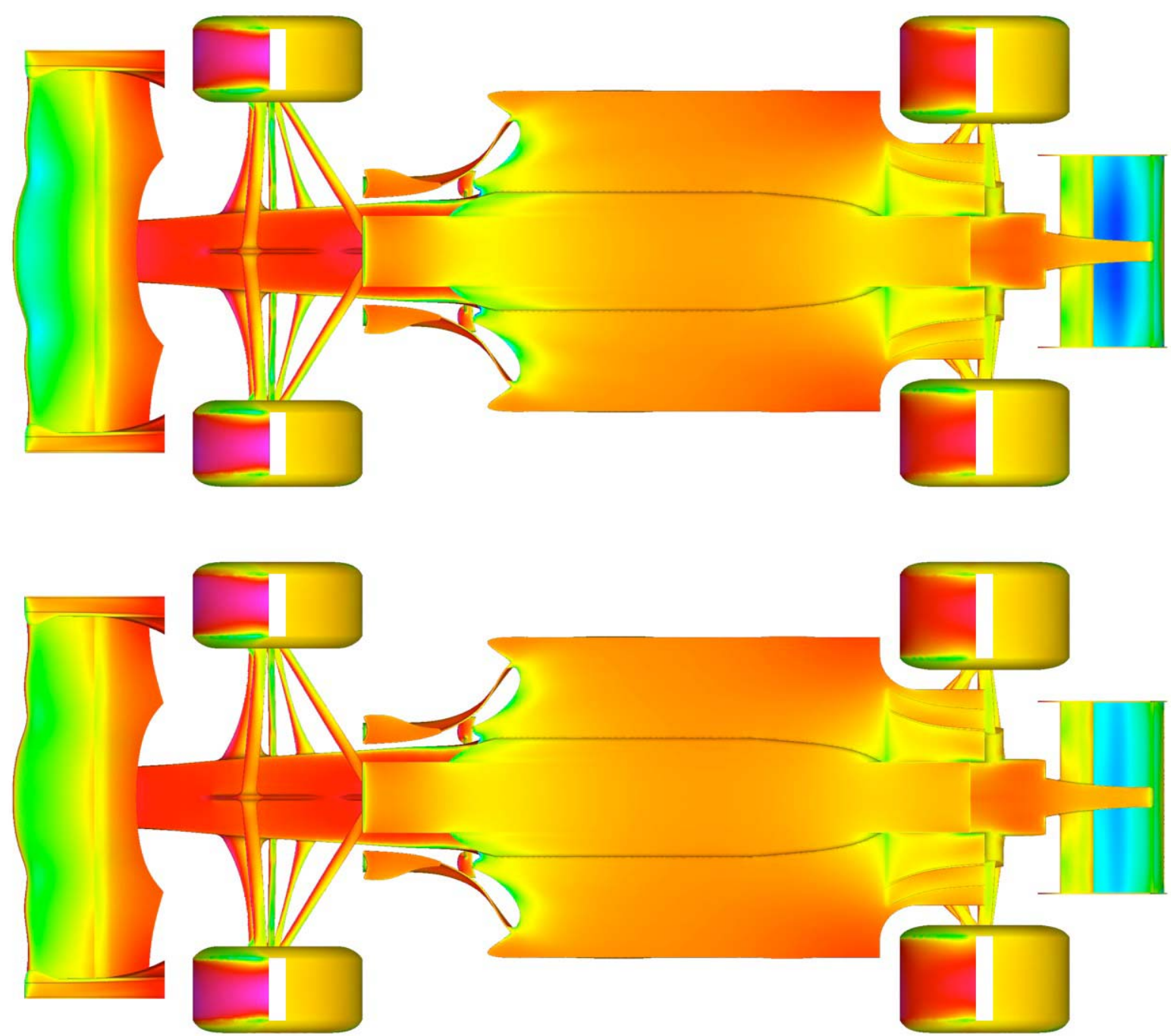

Figure 10. Static pressure underneath leading (top) and following (bottom) 2009 cars when drafting

Compared to a single 2009 car in isolation, the following car's rear wing loses $16.9 \%$ of its down force, and the front wing $25.0 \%$. Down force on the second car as a result is a massive $25.7 \%$ lower than the - worse than in 2007. Drag for both vehicles is reduced when compared to their baseline values in isolation. Table 3 highlights the changes in down force and drag for both cars when drafting, using an isolated car as the baseline.

Table 3. Effects of drafting on 2009 Formula 1 car

\begin{tabular}{|l|c|c|}
\hline & Down force vs single car & Drag vs. single car \\
\hline Lead car & $+0.6 \%$ & $-1.1 \%$ \\
\hline Following car & $-25.7 \%$ & $-4.6 \%$ \\
\hline
\end{tabular}

That the regulations would have such an opposite effect is non-intuitive. The reduced down force and removal of winglets should create a cleaner wake for following cars and reduce the coupling between vehicles in draft configurations. But the results show the exact opposite because, though the 2009 model creates a cleaner wake, the wake's effects have shifted to parts of the car that were previously insensitive. That is, the cleaner wake is concentrated on different aerodynamic elements that were previously insensitive to leading cars. Compared to 2007, 
the undertray and front wing of the $2009 \mathrm{~F} 1$ car are significantly more sensitive to the wakes of leading cars. Table 4 compares the performance losses for the three major aerodynamic components under the 2007 and 2009 regulations.

Table 4. Performance losses for major aerodynamic components

\begin{tabular}{|c|c|c|}
\hline Component & Down force losses for 2007 & Down force losses for 2009 \\
\hline Entire car & $17.4 \%$ & $25.7 \%$ \\
\hline Rear wing & $24.1 \%$ & $16.9 \%$ \\
\hline Underbody & $6.3 \%$ & $14.2 \%$ \\
\hline Front wing & $11.7 \%$ & $25.0 \%$ \\
\hline
\end{tabular}

As shown in the table, the front wing and underbody losses for 2009 are more than twice what they are for the 2007 car. The rear wing on the other hand, has significantly less loss in 2009 than in 2007. The reduction in down force should mean less down force and a cleaner wake with higher dynamic pressure. Close inspection of the wakes show why the rear wing sensitivity is improved while the front wing and undertray sensitivity is exacerbated.

Figure 11 and Figure 12 show contours of velocity magnitude at the vehicle and front wheel centerlines, respectively. In both of these figures the ranges for velocity magnitude are consistent and the 2007 cars are shown on top and the 2009 cars on the bottom.

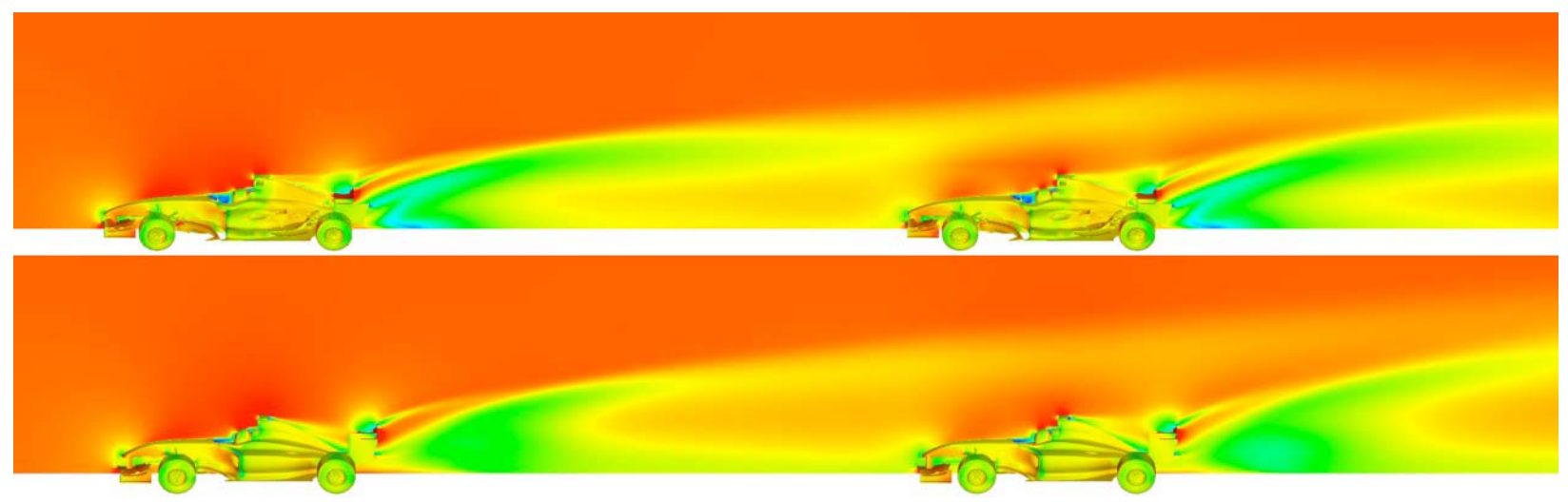

Figure 11. Contours of velocity magnitude at the 2007 (top) and 2009 (bottom) vehicle centerlines

The wake of the car, though less severe overall, is significantly stronger near the ground under the new regulations. In Figure 11 the upper portion of the wake formed by the merging of the wing tip vortices is much stronger for the 2007 car; it extends behind the car nearly 1.5 times further compared to the 2009 model. The increased strength of this upper wake explains why the 2007 rear wing loses more of its performance than the 2009 rear wing.

But the lower portion of the wake, dominated largely by the merging of the tire wakes, is much stronger for the 2009 cars. This lower wake extends many times further behind the leading than in 2007. Because air flowing underneath the car is largely drawn near the ground and from the center portion of the car, the effect on the undertray is significant. Similarly, the center section of the front wing is closest to the ground and because of the front wheels' effects, most front wing down force is drawn from the center section of the wing. The much stronger wake directly above the ground is the reason the 2009 front wing and undertray experience greater losses than the 2007 cars'. This trend of a stronger upper wake under the 2007 regulations and a stronger lower wake under the new regulations is clearly present in both Figures 11 and 12. 

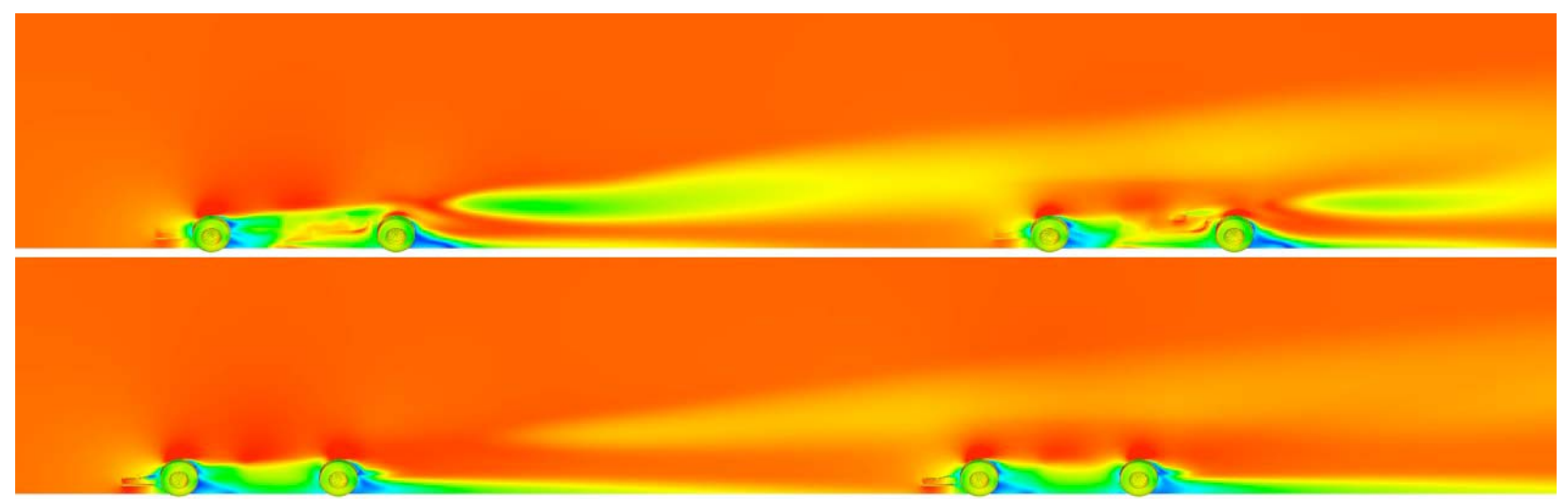

Figure 12. Contours of velocity magnitude at the 2997 (top) and 2009 (bottom) front wheel centerlines

Figure 13 highlights identical trends to those found in Figures 11 and 12, presenting contours of velocity magnitude 1 and $4.5 \mathrm{~m}$ ( 1 car length is $4.4 \mathrm{~m}$ ) behind the leading cars. The upper portions of the 2007 cars' wakes are considerably stronger than those for the 2009 cars at both distances. The wake for the 2007 car also extends further away from the car centerline, due to the increased span of the rear wing. This reduced wake strength away from the ground is what has made the 2009 rear wing less sensitive than before. In this regard, the new regulations are successful.

But the wake near the ground is worse under the 2009 regulations. This stronger lower wake, namely the rear tire wake, is most likely the result of the increased width of the rear tires and elimination of bodywork in front of them. The location of the tire vortex is benign $1 \mathrm{~m}$ behind the car, but the tire vortices from both rear wheels move towards the centerline of the car further downstream, directly into the region from which front wing and underbody flow is drawn.
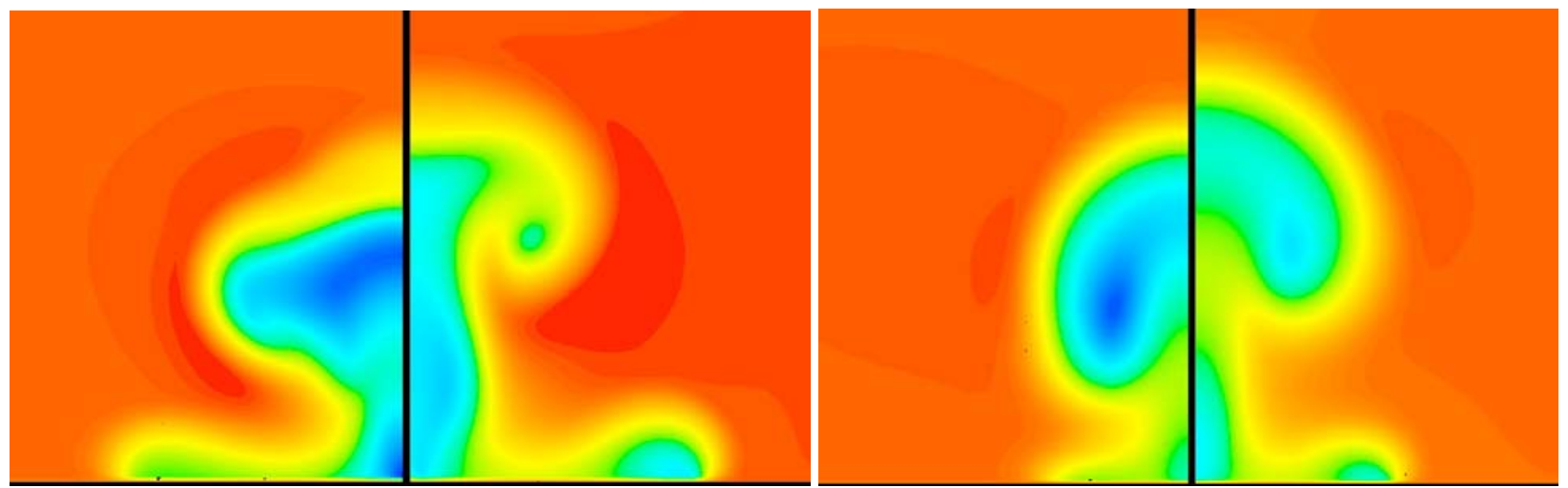

Figure 13. Contours of velocity magnitude $1 \mathrm{~m}$ (left) and $4.5 \mathrm{~m}$ (right) behind the leading cars in both image pairs, the darker wake shown on the left side represents the 2007 car and the lighter wake shown right the 2009 car.

Thus the FIA's decision to eliminate body work has hurt the following car's performance. By removing bodywork near the rear tire and widening the tire, performance on the two elements that previously were least sensitive - the tray and front wing - is dramatically reduced. While the elimination of body work has cleaned up the wake for the upper half the of the car, it has increased wake strength for the lower half. Such is the heavily coupled and complicated nature of F1 aerodynamics. Simply banning aerodynamic components does not mean their disadvantages will be alleviated. When dealing with highly complex and coupled problems, making intuitive change can, and in this case has achieved, the complete opposite effect.

\section{Conclusion}

The 2009 Regulations are unlikely to improve the racing spectacle. The key problem targeted by the regulations - reducing the coupling between cars - has been exacerbated, and the regulations have performed the exact opposite of their original intent. The additional goals of cutting down force and drag $50 \%$ were also not accomplished. 
Luckily, the results give useful insight in understanding why the rules may not work. Perhaps the biggest potential lies in the undertray.

The undertray is the least sensitive and most efficient major aerodynamic element on the car. When a driver approaches another car in front of him, his car loses most of its down force from the front and rear wings, but a very small amount from the underbody. Increasing the percentage of a car's down force generated by the undertray would significantly decrease the coupling between cars in proximity. In an age of ever increasing fuel costs and environmental consciousness, underbody aerodynamics is also more relevant to road cars than extreme high lift wings and treatment of uncovered wheels.

Widening the allowable bodywork between the axles would allow for better handling of airflow over the rear tire, and increasing the rear wing span would reduce the severity of the wing tip vortices. This in turn would help the FIA meet it's target of $50 \%$ drag reduction. Decreasing the rear wing chord would further decrease drag and reduce down force, and loss of rearward aerodynamics bias could be supplemented by extending the undertray diffuser rearward. The rear wing and tire wakes are the largest and have the greatest impact on following cars. Opening up the regulations to allow for innovative treatment of the rear tires, and moving to smaller, more efficient rear wings are both simple concepts with great potential for success.

Perhaps more revisions to the regulations will be made before the 2009 season. It certainly appears that major changes are necessary, but is also appears that the lack of passing due to aerodynamics can be solved in a number of ways.

\section{Appendix A. Additional Mesh Images}

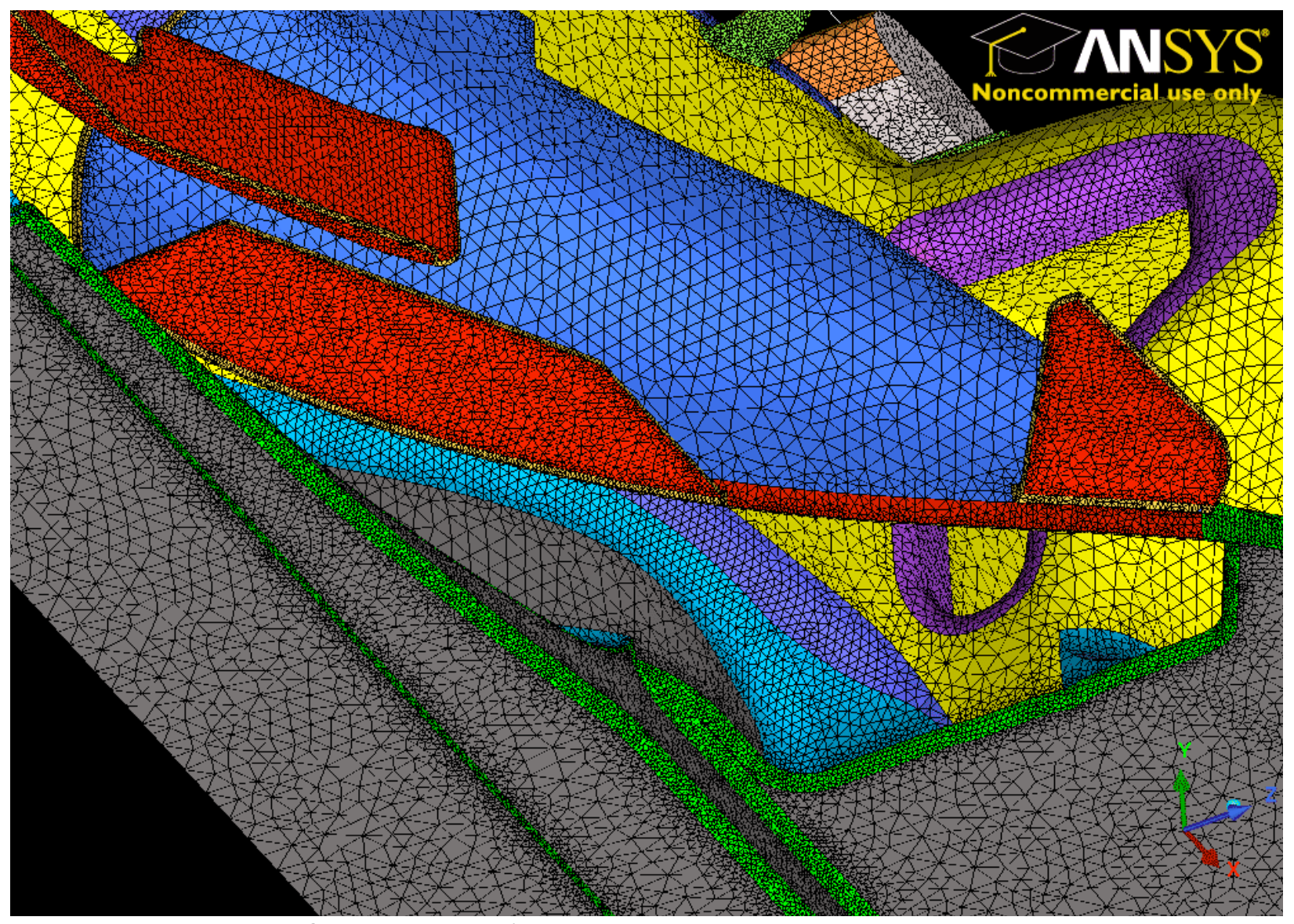

Vortex generator surface mesh detail 


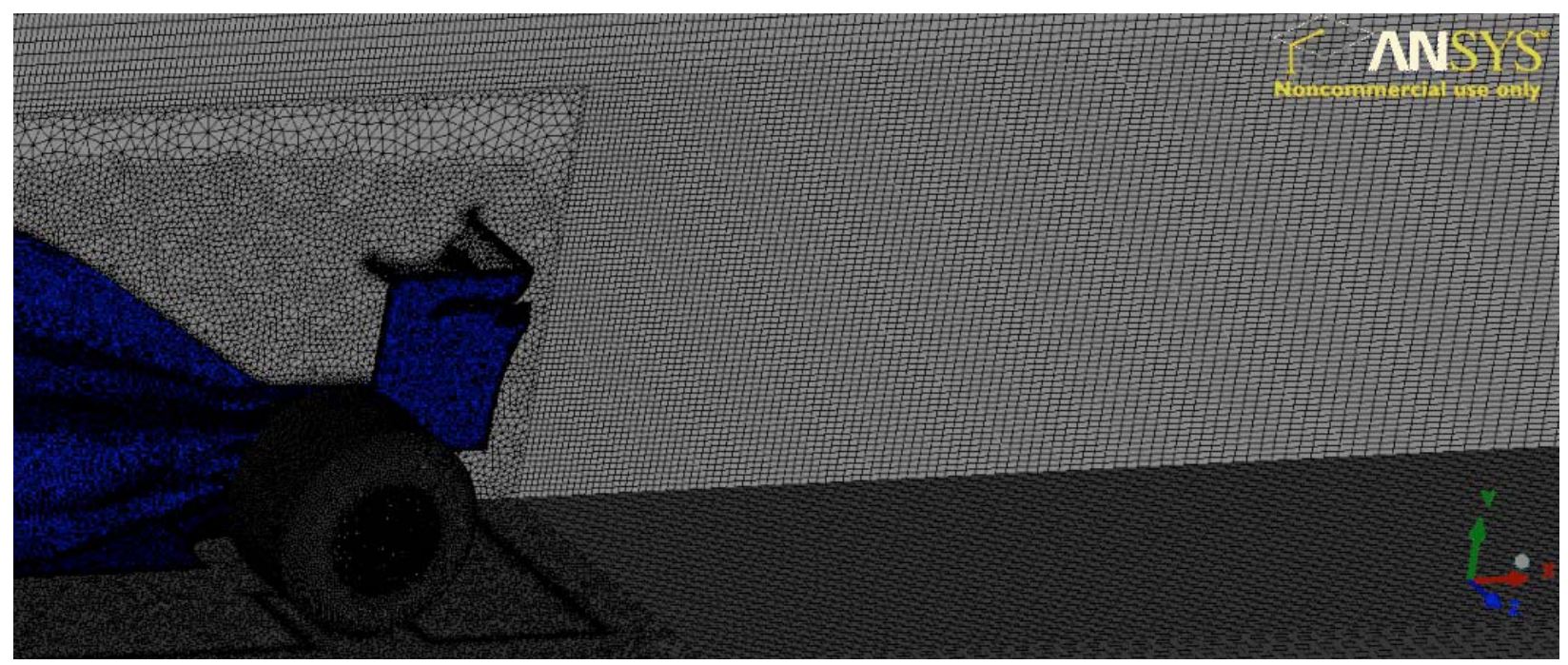

Mesh topology behind leading 2009 car cell growth rate behind the leading car is less than $1 \%$ to ensure full capture of the wakes and interactions between the cars

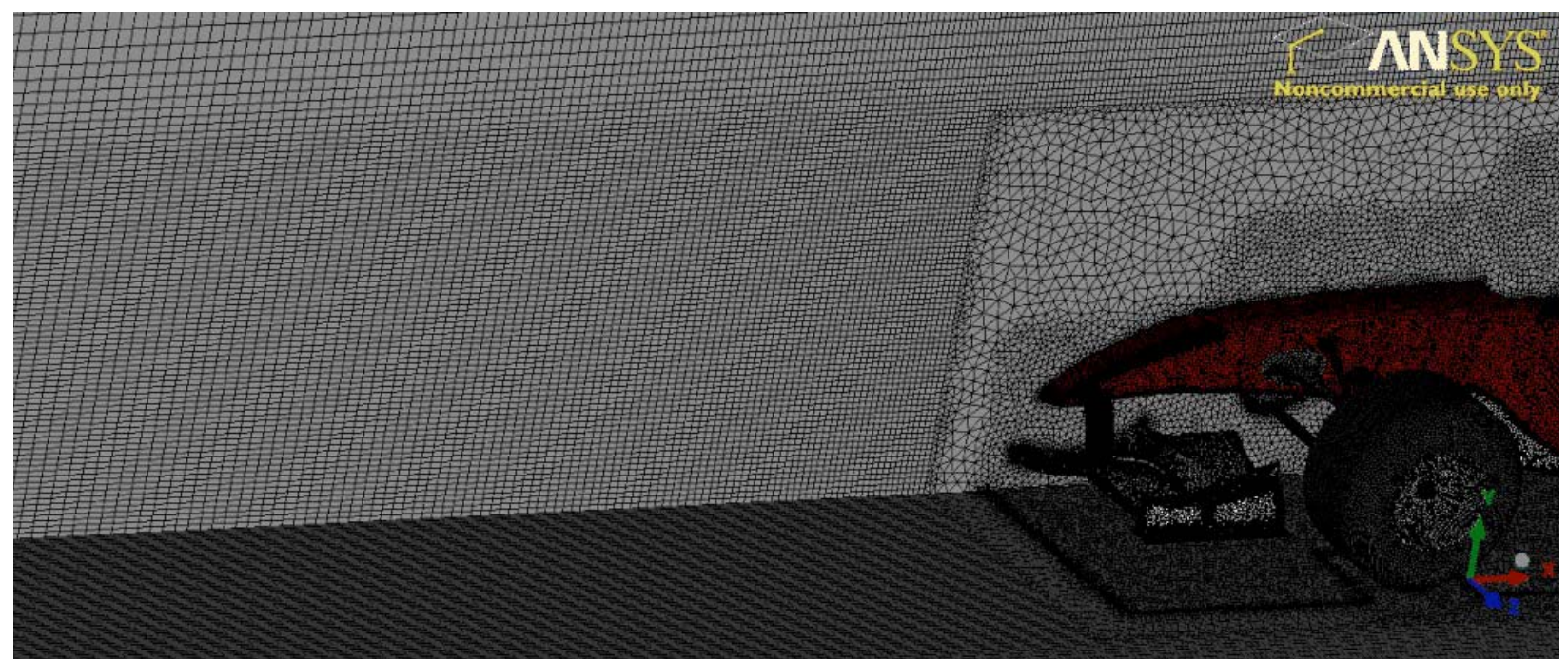

Mesh topology in front of trailing 2009 car cell growth rate in front of the following car is less than $1 \%$ to ensure full capture of the wakes and interactions between the cars 


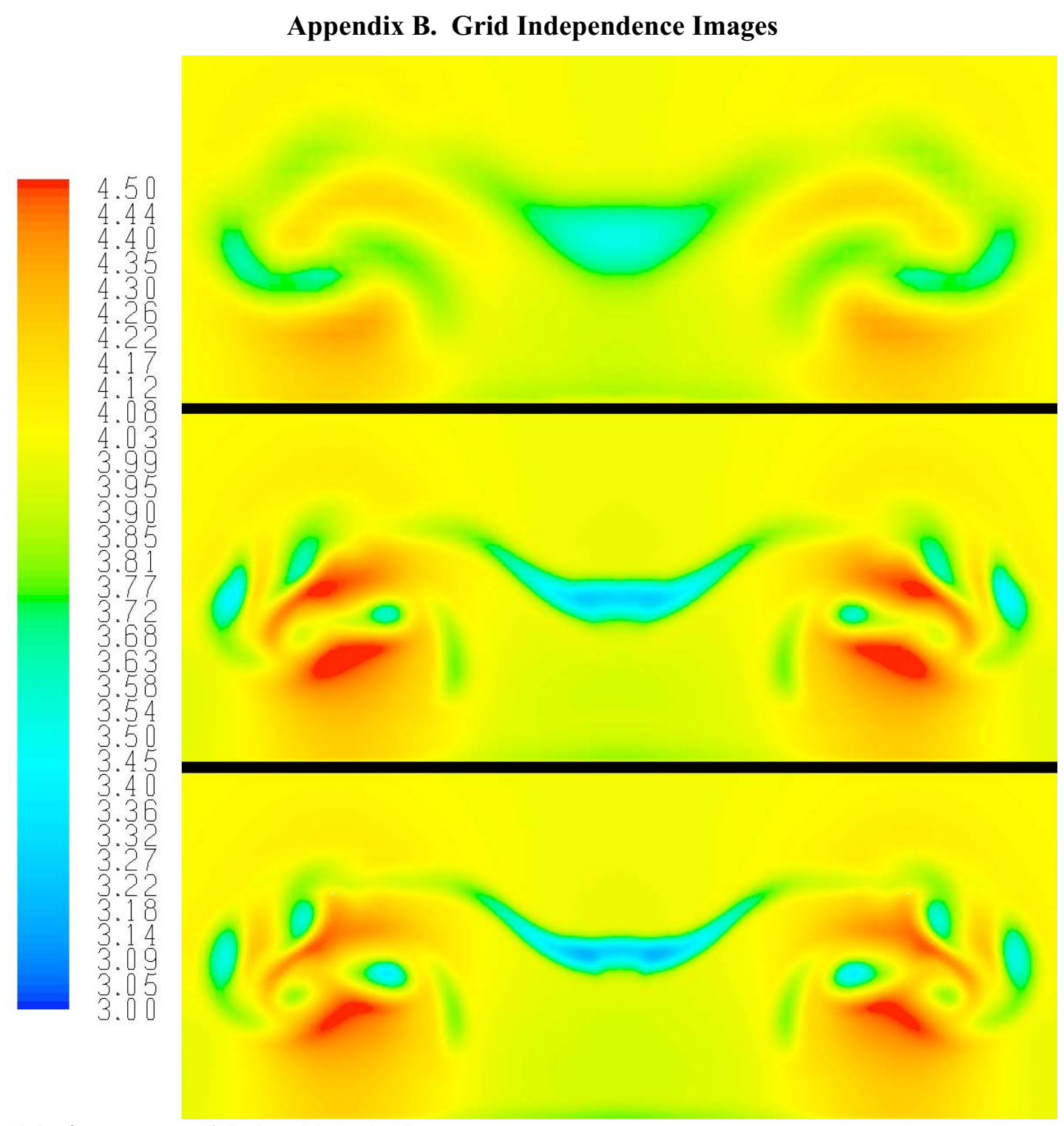

Velocity contours 1.5 chord lengths downstream 

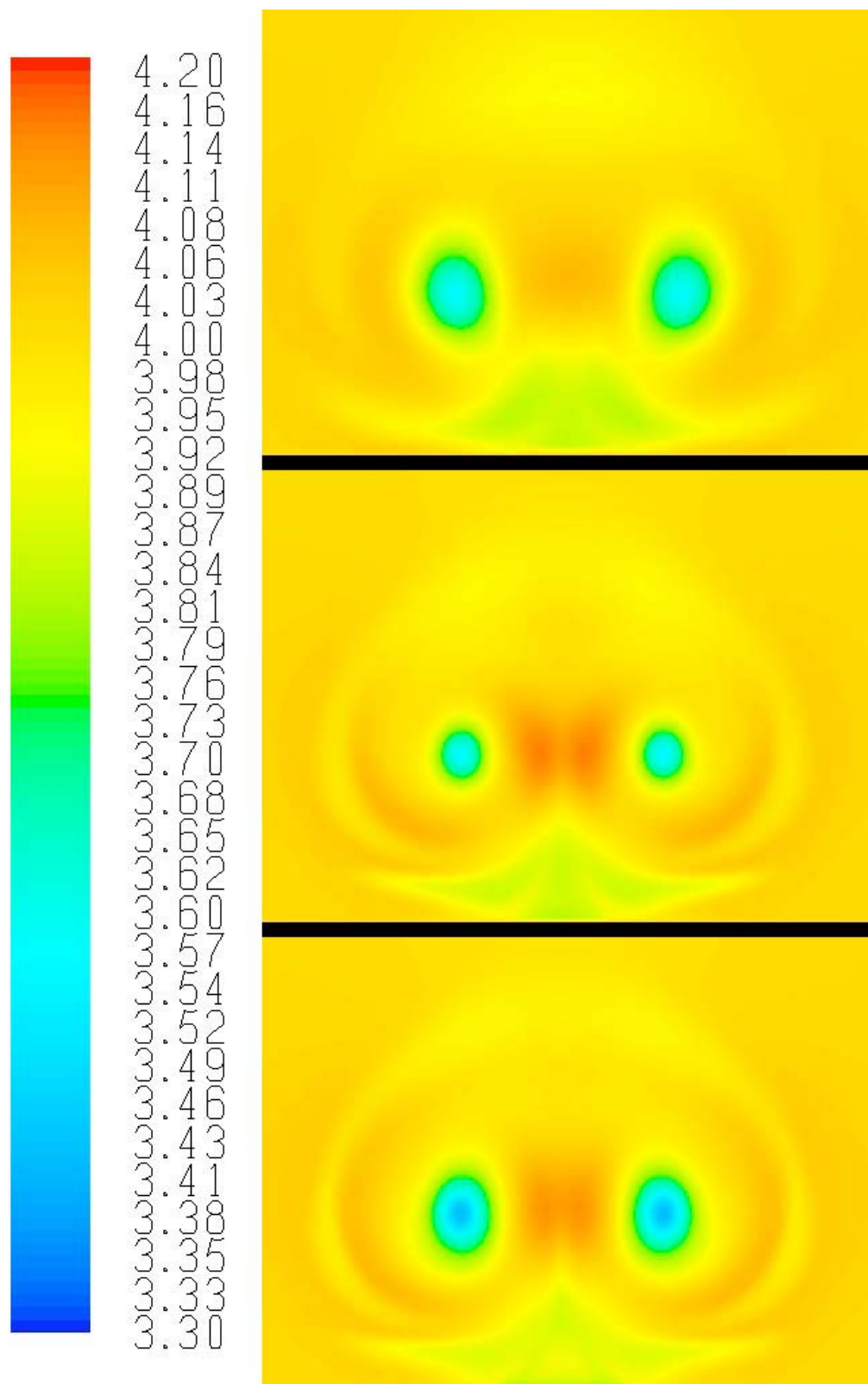

Velocity contours 10 chord lengths downstream

\section{Acknowledgments}

Thanks to Miqdad Ali for his advice and teachings, and the practical knowledge of open wheel aerodynamics and applied CFD he so kindly shared. Many thanks as well to Dr. Diana Franklin and Greg Porter of the California Polytechnic State University Computer Science Department, for generously allowing access to the ravel computing cluster. This research could not have been completed without the computing power of ravel and Greg's assistance in setting up and executing batch CFD runs. Robert L. Perry also thanks Professor John Fabijanic for their advice and guidance. 


\section{References}

${ }^{1}$ Federation Internationale De L'Automobile, "2009 FIA Formula 1 World Championship Technical Regulations" URL: http://217.204.13.141/sport/Regulations/flregs.html [cited December 2007]

${ }^{2}$ ICEM CFD Computational Fluid Dynamics Pre-processor, Software Package and Product Documentation, Version 11.0.1, Ansys Inc., Canonsburg, Pennsylvania.

${ }^{3}$ Wilcox, David C., Turbulence Modeling for CFD, $3^{\text {rd }}$ Edition, DCW Industries, Inc., 2006, pp. 181-182.

${ }^{4}$ Fluent Computational Fluid Dynamics Solver, Software Package and Product Documentation, Version 6.3.26, Ansys Inc., Lebenon, New Hampshire.

${ }^{5}$ Larsson, Torbjörn, "BMW Sauber F1 Team: Next Chapter in F1 Aerodynamics Design," Forschungsinstitut für Kraftfahrwesen und Fahrzeugmotoren Stuttgart, July 2007 Conference.

${ }^{6}$ Perry, Robert L., "Investigation of the Proposed 2009 FIA Formula 1 World Championship Aerodynamic Regulation Changes Using Computational Fluid Dynamics," Master's Thesis, Aerospace Engineering Department, California Polytechnic State University, San Luis Obispo, CA, 2008.

${ }^{7}$ BMW Sauber F1 Team, "Engine Specifications," URL: www.bmw-sauber-f1.com [cited December 2007]

${ }^{8}$ Abbot, I. H. and Von Doenhoff, A., Theory of Wing Sections: including a summary of airfoil data, Dover Publications, New York, 1959, pp. 488-489.

${ }^{9}$ Katz, Joseph, Race Car Aerodynamics - Designing for Speed, Robert Bentley Automotive Publishers, Cambrige, MA, 1995.

${ }^{10}$ A. F. Skea and P. R. Bullen, "CFD Simulations and Experimental Measurements of the Flow Over a Rotating Wheel in a Wheel Arch," SAE Paper No. 2001-01-0487, 2000. 